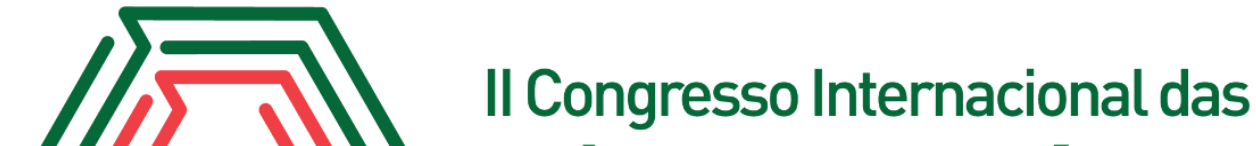 Ciências Agrárias COINTER - PDVAgro 2017
}

\section{CONJUNTURA DO MERCADO DA PIMENTA-DO-REINO NO PARÁ}

\author{
Apresentação: Comunicação Oral \\ Leandro do Rosario Silva ${ }^{1}$; Larissa Ferreira de Lima $^{2}$; Luana do Socorro Freitas Souza ${ }^{3}$; \\ Bruno Wendell de Freitas Pereira ${ }^{4}$; Rafael Gomes Viana ${ }^{5}$;
}

\section{Resumo}

A espécie de pimenta-do-reino (Piper nigrum L.) pertencente à família Piperaceae, se estabeleceu como cultivo racional após a introdução da cultivar Cingapura pelos imigrantes japoneses no estado do Pará. No Brasil foi introduzida no século XVII pelos também japoneses. Esta cultura apresenta grande produtividade quando manejada de maneira correta, seu fruto é um dos condimentos mais valorizadas do mundo, sendo bastante utilizado na gastronomia e produtos industrializados. Possui grande valor econômico, porém com oscilações de preços, no entanto permite que a atividade desenvolvida pelos produtores proporcione alta rentabilidade.

O objetivo deste trabalho foi caracterizar e desenvolver análise das características da cadeia produtiva da pimenta-do-reino, através de revisão de literatura existente e agrupamento de dados estatísticos a fim de explicar o comportamento do produto no mercado em escala internacional, nacional e regional, de modo a contribuir para a orientação dos agentes econômicos da atividade. Para isso, foi realizado uma revisão das literaturas envolvendo a cultura e a criação de gráficos, quadros e tabelas com base em dados provenientes de fontes oficiais da agricultura.

No panorama internacional a produção de pimenta-do-reino se destaca em países como Vietnã, Indonésia, Índia e Brasil. Já os maiores importadores, ganha destaque os Estados Unidos da América, Alemanha e Países Baixos. Enquanto, no que tange o panorama

\footnotetext{
1 Graduando em Agronomia da Universidade Federal Rural da Amazônia, Campus Belém, E-mail: leandrorsilva65@gmail.com

${ }^{2}$ Graduando em Agronomia da Universidade Federal Rural da Amazônia, Campus Belém, E-mail: Ilimalari@hotmail.com

3 Graduanda em Agronomia da Universidade Federal Rural da Amazônia, Campus Belém, E-mail: luannafreitas1@gmail.com

4 Professor Doutor da Universidade Federal Rural da Amazônia, Instituto Ciber Espacial, E-mail: brunowendell@yayoo.com.br

5 Professor Doutor da Universidade Federal Rural da Amazônia, Instituto de Ciências Agrárias, E-mail: rafael.gomes@ufra.edu.br
} 
regional a produção de pimenta-do-reino se destaca em três regiões que são as regiões Norte, Nordeste e Sudeste, sendo a região Norte a maior produtora nacional, em destaque o estado do Pará seguido pelo estado do Espirito Santo no Sudeste e Bahia no Nordeste.

Palavras-Chave: Cultivar Cingapura, Economia, Produção.

\section{Introdução}

A pimenteira-do-reino (Piper nigrum L.) é uma planta trepadeira pertencente à família Piperaceae. É originária da Índia e introduzida no Brasil no século XVII pelos japoneses. As principais utilizações da pimenta-do-reino são: tempero de alimentos, principalmente nos industrializados, como salame, salsicha, mortadela, presunto, e nas indústrias farmacêutica e de cosméticos (PRABHAKARAN \& NAIR, 2011 apud LOURINHO et al., 2014).

Após a introdução da cultivar Cingapura pelos imigrantes japoneses em 1993, no Estado do Pará, a espécie se estabeleceu como cultivo racional. O Brasil, até a década de 40, embora produzisse pimenta-do-reino, importava parte do que consumia, tornando-se autosuficiente apenas em 1950 (DESER, 2008). Na década de 80, mais precisamente nos anos de 1980 a 1983, o Brasil se tornou o país que mais produziu pimenta-do-reino em todo o mundo e nos anos de 1980 a 1982 e em 1984, alcançou a posição de maior exportador mundial de pimenta-do-reino, em função da produção paraense. Em 1990 e 1991, apesar da crise, a produção de pimenta-do-reino atingiu novo recorde mundial idêntico aquele verificado em 1982 (HOMMA, 2008).

Nesse contexto, dois Estados brasileiros vêm se destacando na produção de pimentado-reino: Pará (PA), com 79\%, e Espírito Santo (ES), com 13\% da produção nacional (IBGE, 2014). Sendo o Estado do ES o que apresenta o cultivo mais tecnificado, com mais de $80 \%$ da área cultivada sob sistema de irrigação, o que propicia maiores produtividades, quando relacionado com o Estado do Pará (SERRANO et al., 2006; PARTELLI, 2009 apud LOURINHO et al., 2014).

De acordo com o quadro delineado acima, a abordagem deste estudo tem como objetivo caracterizar e desenvolver a análise das características da cadeia produtiva da pimenta-do-reino a fim de explicar o comportamento do produto no mercado em escala internacional, nacional e regional, de modo a orientar os agentes econômicos da atividade.

\section{Fundamentação Teórica}

O trabalho foi estruturado em 6 seções, além da introdução. Na segunda seção descreveu-se sobre o mercado mundial da pimenta-do-reino. Na terceira, sobre o cenário nacional e na sequência sobre o mercado estadual. Na quinta seção, tem-se os resultados desta 
pesquisa. E por fim, uma conclusão sobre o tema possibilitando um melhor entendimento dos dados coletados.

\section{Metodologia}

Para o desenvolvimento do trabalho, foi realizado uma revisão da literatura envolvendo a pimenta-do-reino em todos os aspectos, abrangendo desde a parte botânica até a cadeia produtiva. Além disso, foi elaborado gráficos e tabelas com base em dados provenientes de fontes oficiais da agricultura, tais como o Instituto Brasileiro de Geografia e Estatística (IBGE) e Food and Agriculture Organization of the United Nations (FAO).

\section{Resultados e Discussão}

\section{CONJUNTURA DO MERCADO INTERNACIONAL}

O cultivo da pimenta-do-reino ocorre, predominantemente, na Ásia, Américas do Sul e Central e na África. De acordo com a figura 1, nota-se que a área colhida e a produção de pimenta-do-reino nos últimos 19 anos vêm crescendo. Observa-se que as maiores produtividades ocorreram nos anos de 1990, percebe-se que nos anos de 2005-2012, essa variável decresceu, voltando a crescer somente em 2012. Isso possivelmente é explicado em função da função dos problemas com questões fitossanitárias (fusariose) e ciclo de preços, que afetaram de forma significativa a produção (FILGUEIRAS et al., 2004).

Figura 1 - Evolução da área colhida, produção e produtividade da pimenta-do-reino no mundo, 1995-2014.

\section{(Fonte: FAO 2017).}

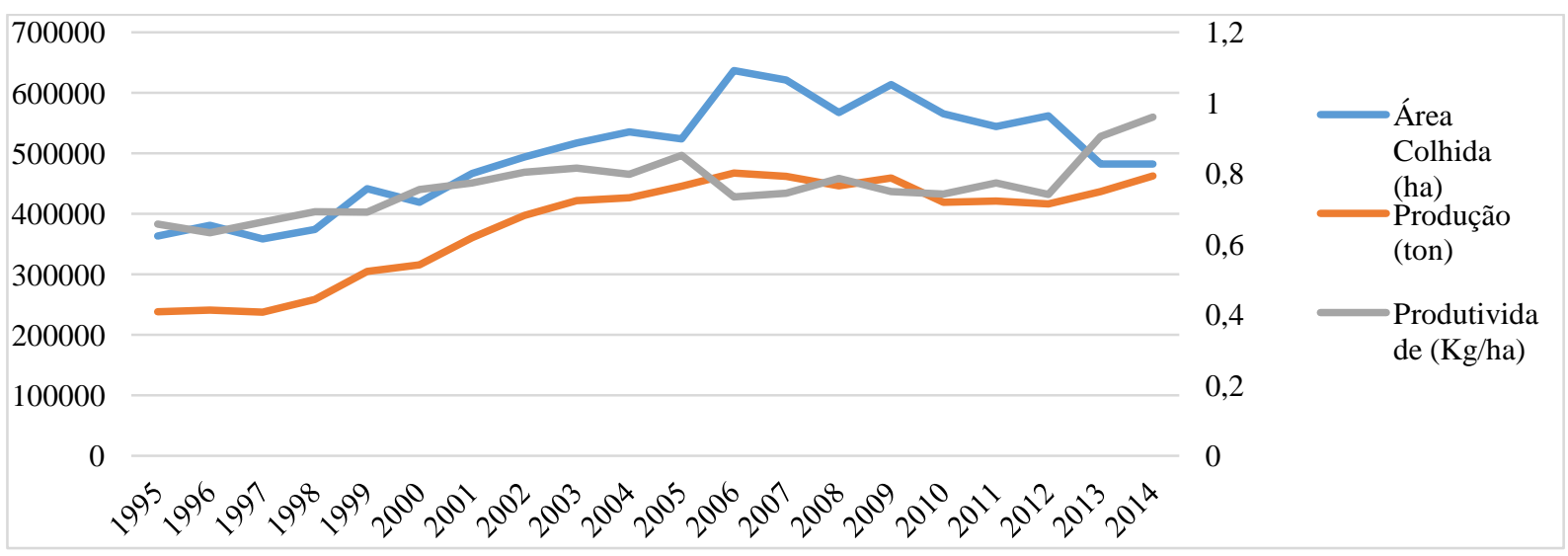

No que diz respeito às exportações, tem-se na Figura 2 os países que mais se destacaram entre o período de 1995 a 2013. Em 1995, a Indonésia era o maior exportador de pimenta-do-reino, acompanhado de perto pela Singapura e Índia. A partir de 1996, a Indonésia vai perdendo destaque nas exportações e a Singapura e Brasil vão ganhando destaque. 
Nesse período, a participação do Vietnã no comércio exterior da pimenta-do-reino era praticamente ínfima. A partir de 2001 assumiu a liderança desse mercado, mantendo-se nesse patamar até os dias atuais, sendo que em 2009 sua participação atingiu o patamar seu índice mais alto no comércio exterior com 134.300 toneladas de pimenta-do-reino.

Um dos possíveis fatores que explicam a hegemonia do Vietnã no comércio de exportação, é que com a crise que ocorreu com os países na década de 1980, houve uma super oferta do produto, que associado aos elevados custos de produção, problemas com fitossanidade reduziram a produção dos demais países. Nesse viés, o Vietnã ampliou seu market-share, o que proporcionou uma produção com custos baixos e mão-de-obra (FILGUEIRAS et al., 2004).

Figura 2 - Evolução das exportações mundiais de pimenta-do-reino, segundo os principais países: 1995-2013.

(Fonte: FAO 2017).

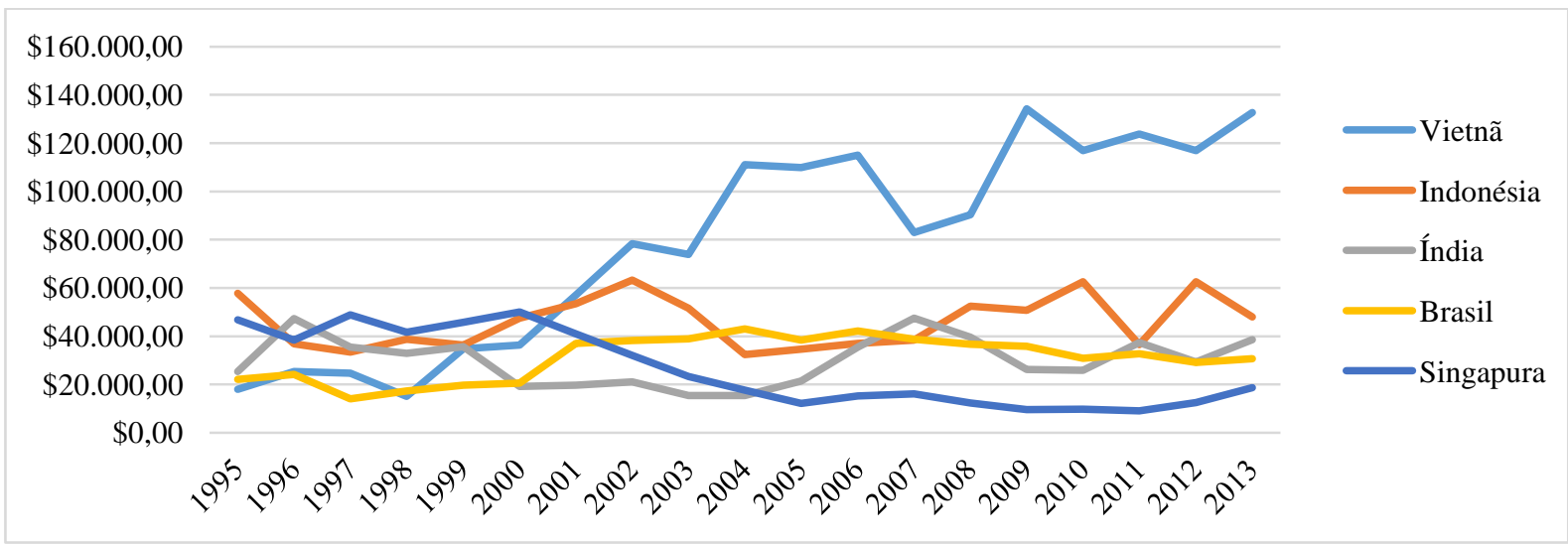

No que se concerne as importações mundiais de pimenta-do-reino, os países que mais importam o produto nos anos de 1995-2013 foram: Estados Unidos da América, Alemanha, Países Baixos, Singapura e Índia FAO 2017.

De acordo com o gráfico abaixo, os EUA é o maior importador de pimenta-do-reino do mundo, importando cerca de 1.148.622 toneladas do produto no período analisado. Isso possivelmente pode ser explicado em função do consumo do país. A pimenta-do-reino é muito utilizada principalmente nos industrializados, que são amplamente utilizados nas redes de fastfood. 
Figura 3 - Evolução das importações mundiais de pimenta-do-reino, segundo os principais países: 1995-2013.

(Fonte: FAO 2017).

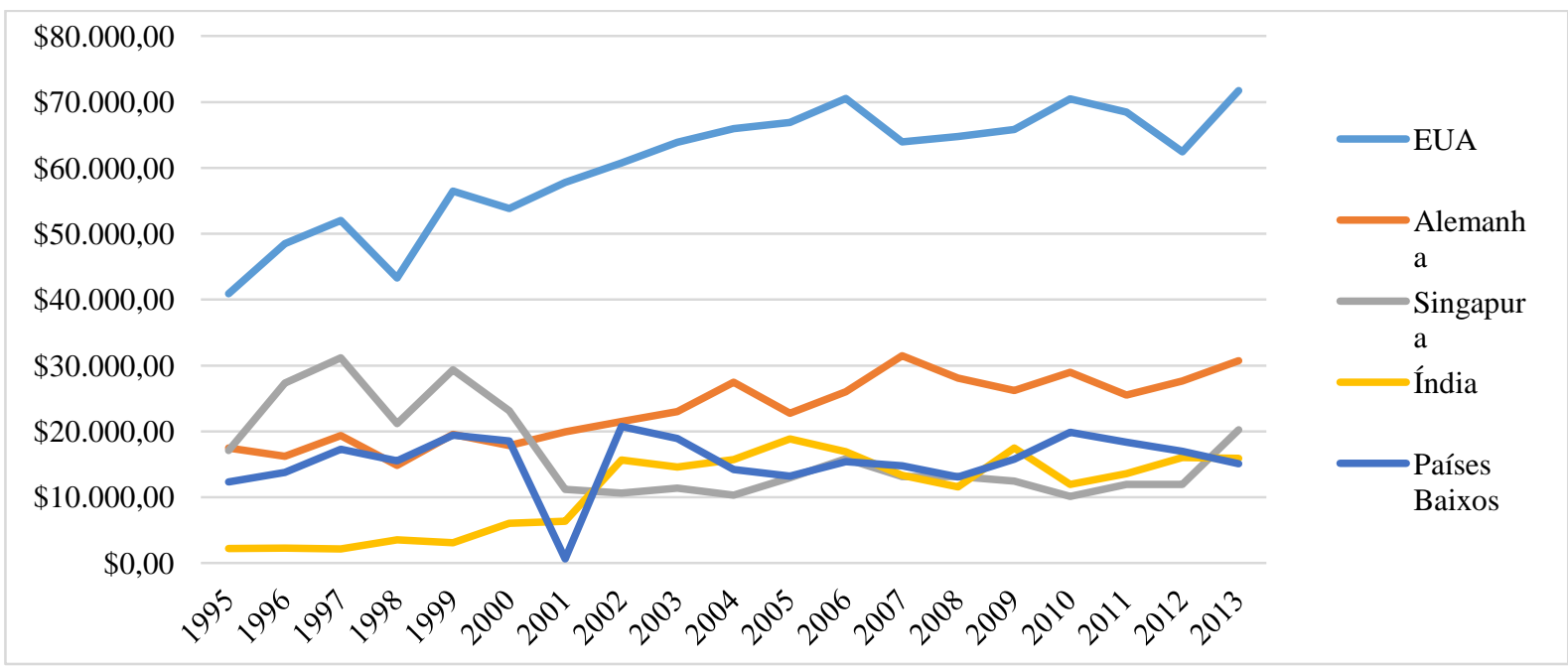

Com relação aos preços nas últimas três décadas o mercado internacional de pimentado-reino, o gráfico abaixo (Figura 4) ilustra a evolução dos preços internacionais do produto no comércio exterior.

Figura 4 - Evolução dos preços internacionais da pimenta-do-reino no período 1995-2013. (Fonte: FAO 2017).

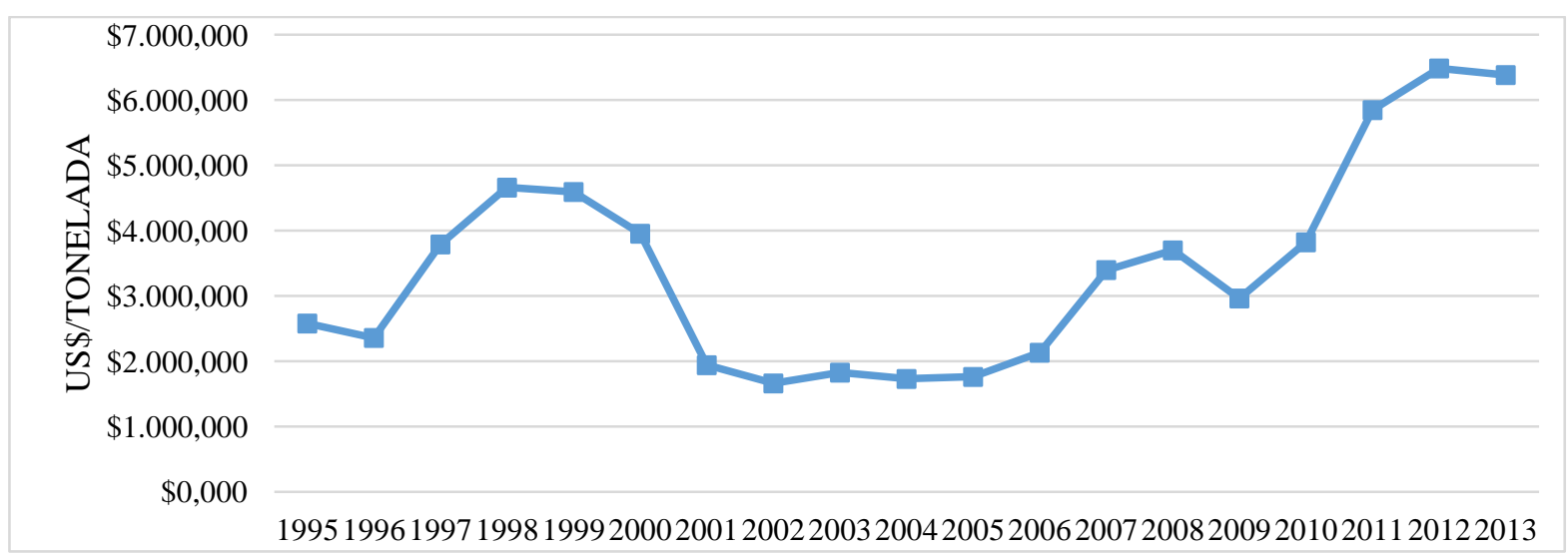

As colunas apresentam a evolução do preço das exportações, em US\$/tonelada, e a linha o comportamento dos preços no decorrer dos anos. Nesse período observa-se que os picos ocorreram no final das décadas de 1990, 2000 e 2010, sendo que os anos com preços mais elevados foram 1998 (US\$ 4. 659,52/tonelada), 2008 (US\$ 3.698,29) e 2012 (US\$ $6.485,52)$.

\section{CONJUNTURA DO MERCADO NACIONAL}

Distribuição e crescimento da produção

Fazendo uma análise dos principais estados do Brasil que produzem pimenta-do-reino, conforme demonstra a figura 5, no total de quantidade produzida de pimenta -do -reino no Brasil, a maior quantidade de produção é no estado do Pará, e este, por conseguinte direciona a linha de tendência de produção do País. Portanto, se a produção no estado do Pará cair, 
consequentemente, a produção no Brasil decai e o contrário também é verdadeiro. Ademais, os estados, Espírito Santo e Bahia ocupam o segundo e terceiro lugar no ranking de produção desta cultura, respectivamente, apesar de que a produção destes é bem aquém em relação ao principal produtor nacional. No ano de 2015, o Pará produziu 62 \%, o Espírito Santo $26 \%$ e a Bahia 9\% de pimenta do reino no Brasil (IBGE, 2015).

Figura 5 - Distribuição dos estados Brasileiros com maior produção da cultura da pimenta-do-reino, 1995-2015.

(Fonte: IBGE 2015).

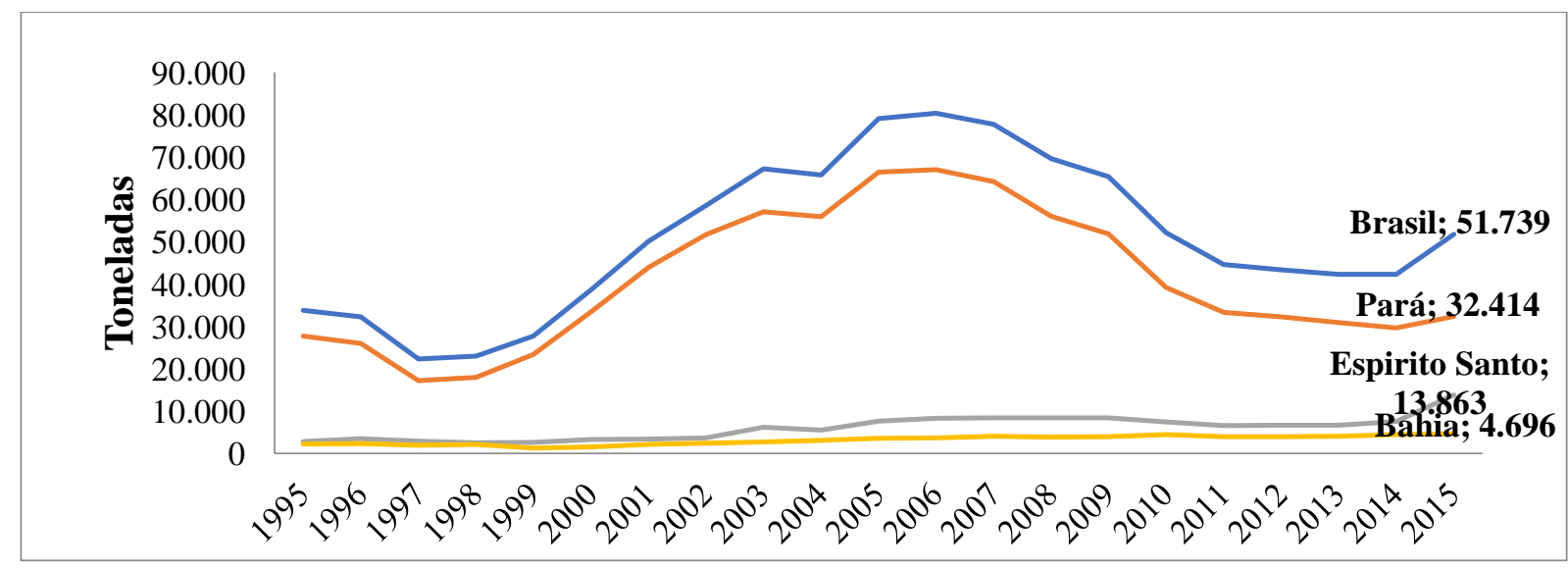

Para entender a conjuntura econômica é necessário avaliar algumas variáveis importantes, como área colhida, produção e produtividade. Na figura 7 percebe-se que, a produtividade não houve uma grande variação durante os anos estudados, segundo Filgueiras et al (2004) uma possível explicação para esse fenômeno é a fusariose, haja vista, que ainda não se obteve cultivares resistentes a essa doença, o que desestimula os produtores, além de outros fatores como a precária infraestrutura para o escoamento da produção e os baixos subsídios.

Diferentemente da produtividade, na produção houve uma elevada variação durantes os anos, haja vista, que de meados até o final da década de 90 foram os anos de menor produção, em 1997 foi o ano de menor produção com aproximadamente 20 mil toneladas, porém começou a crescer de forma rápida na década de 2000, atingindo o maior índice de produção em 2006, com quase 80 mil ton., ademais, uma possível explicação é a expansão da área colhida nesse ano, porém, a partir de 2008 a produção voltou a cair, chegando atingir cerca de 40 mil ton., no entanto, em 2015 a produção retornou ao crescimento.

A área colhida varia bastante, devido está relacionada com a variação dos preços, quando os preços estão em alta os produtores tendem a aumentar a sua área de colheita e assim, produzirem mais e obterem maiores rendas (FILGUEIRAS et al, 2004). Em 1999 foi um ano de preços altos, chegando a 30 reais o $\mathrm{kg}$, dessa forma, os produtores começaram a ampliar a sua área a partir de 1999, podendo verificar que de 1999 a 2005 só houve 
crescimento da área colhida atingindo em 2005 cerca de 30.000 ha, foi quando em 2005 atingiu um dos menores preços, por conseguinte a área colhida começou a decair, conforme a figura 6 .

Figura 6 - Evolução da área colhida, produção e produtividade da cultura da pimenta-do-reino, 1995-2015. (Fonte: IBGE 2015).

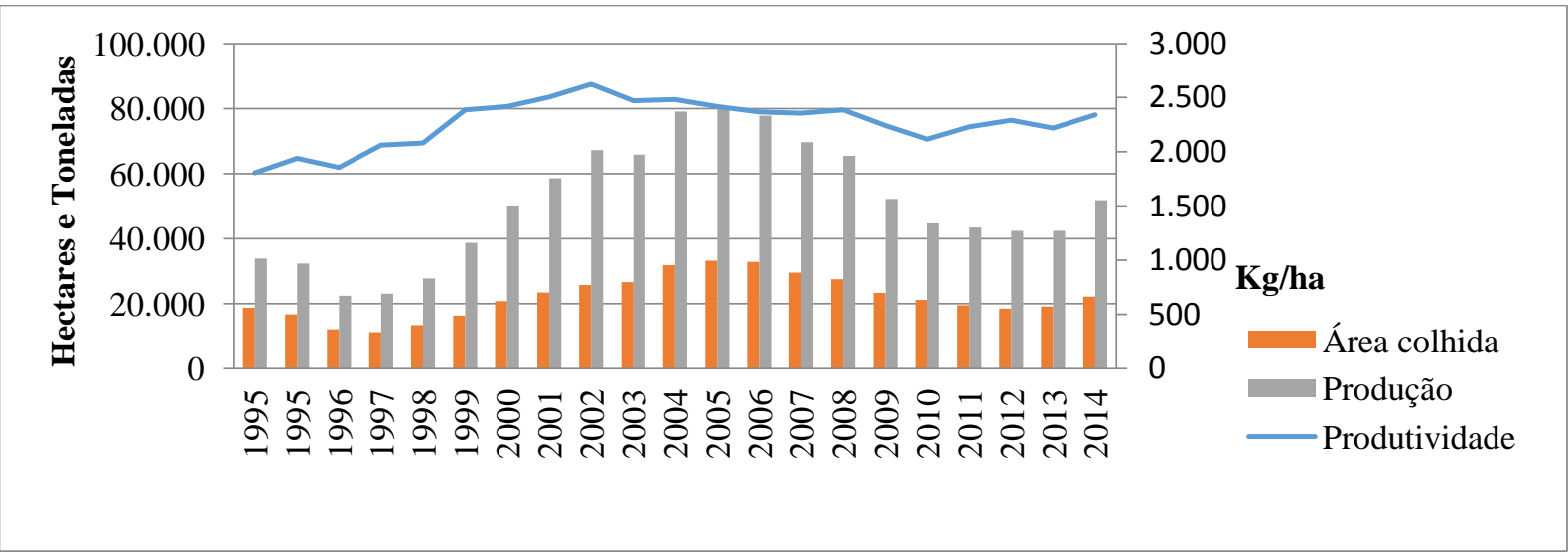

Comportamento dos preços

Sabe-se que a oferta de pimenta é muito inelástica a preço, e a demanda é moderadamente inelástica a preço e a renda, dessa forma, por a pimenta ser uma commodity, no cenário internacional se houver uma valorização cambial há uma queda nas exportações, ocasionando a representação da análise de preços em altos e baixos (FILGUEIRAS et al 2009 apud SANTANA, 1995).

Na figura 7 observa-se o comportamento do preço que revela grandes oscilações, em análise em um intervalo de tempo de 10 anos, em 1995 o kg da pimenta do reino estava cerca de 6 reais, enquanto que em 1999 o $\mathrm{kg}$ chegou a quase 30 reais, porém voltou a cair atingindo preço menor que 5 reais o kg. Segundo Filgueiras et al (2004), essa oscilação dos preços caracteriza uma cultura permanente, ou seja, de ciclo longo e também uma commodity, já que os produtores são tomadores de preços, devido ao mercado internacional ser oligopsônio, ou seja, haver poucos compradores e estes concentram a compra da maior parte da produção, formando os preços. 
Figura 7 - Evolução dos preços da pimenta-do-reino recebido pelos produtores do Brasil desde 1995 até 2015.

(Fonte: IBGE 2015).

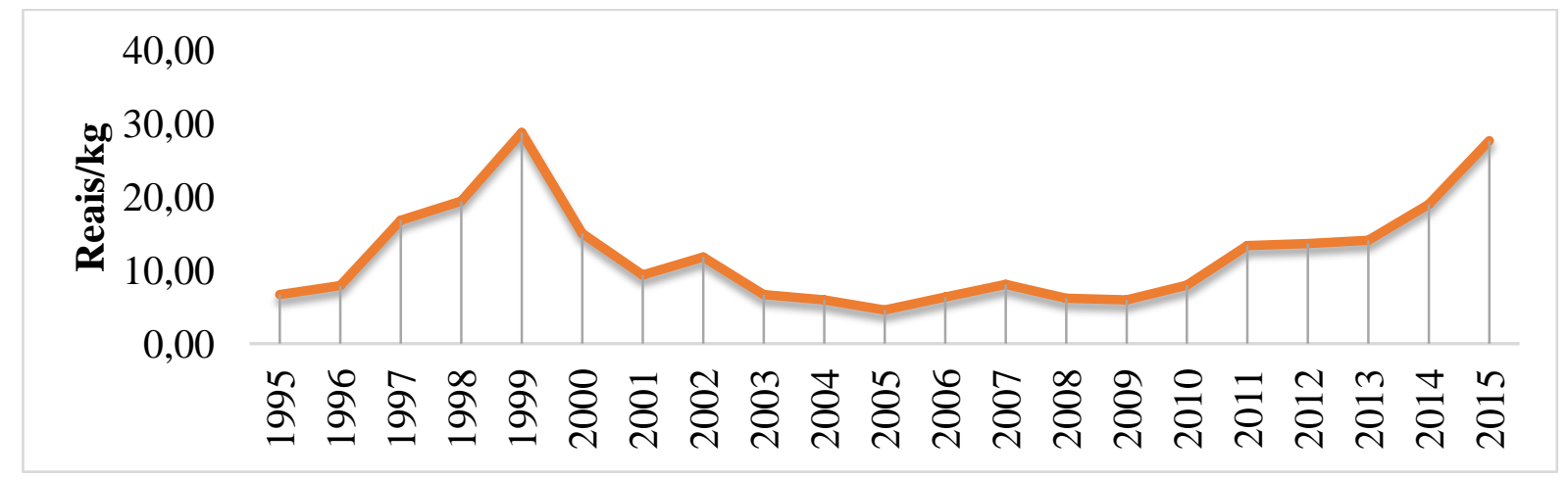

\section{PRODUÇÃO DA PIMENTA- DO- REINO NO ESTADO DO PARÁ.}

Dentre as mesorregiões do Pará o nordeste paraense se destaca com a maior produção, como pode ser observado na figura 9. Em 1995 a produção do nordeste paraense foi de $47 \%$, e nos anos consecutivos a produção só aumentou alcançando no ano de 2000 56\%, no ano de 2005 74\% e no ano de 201587 \% da produção do estado. Dessa forma, mostra-se a importância da mesorregião Nordeste Paraense para a produção de pimenta do reino no País, haja vista, que o estado do Pará é o maior produtor de pimenta- do- reino no Brasil.

Segundo Filgueiras et al (2009) no período de 1998 a 2008, a taxa de crescimento da área colhida das mesorregiões foi de $11,71 \%$ ao ano, no entanto, o nordeste paraense apresentou uma taxa superior de $17,78 \%$ ao ano. Neste mesmo período a taxa de crescimento de produtividade quem obteve maior crescimento foi o sudoeste paraense com 5,79\% ao ano, enquanto que o nordeste paraense obteve taxa de crescimento de 2,25\%, porém, vale ressaltar, que o nordeste paraense utiliza o sistema SAF's o que diminui o número de plantas e consequentemente sua produtividade.

Figura 8 - Distribuição da produção da pimenta -do-reino na s mesorregiões do Pará, 1995-2015. (Fonte: IBGE (015).

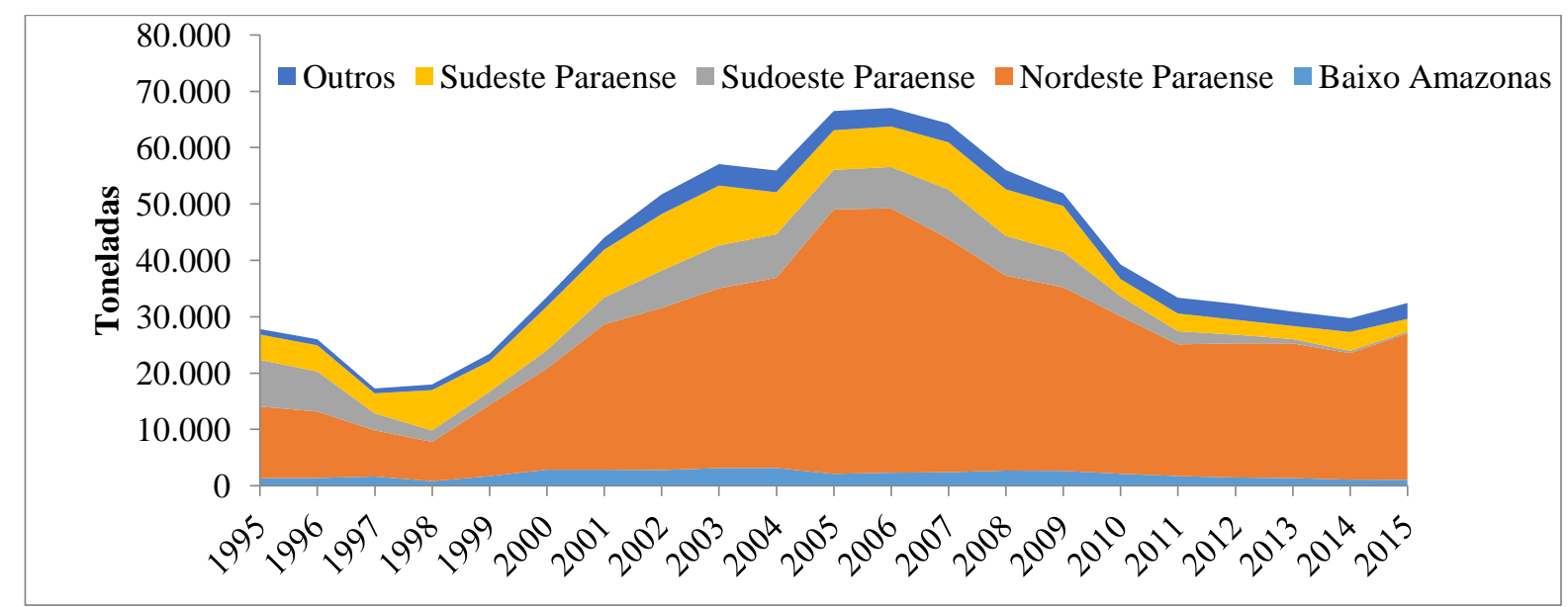


$\mathrm{Na}$ figura 9, ilustra as principais microrregiões produtores de pimenta-do-reino do estado do Pará no ano de 2015, em que mais de $70 \%$ da produção está concentrada na microrregião do Guamá, Tomé-Açu, Cametá e Bragantina.

Figura 9 - Microrregiões do Pará que possuem maior produção de pimenta do reino em 2015. Fonte: IBGE

(2015).

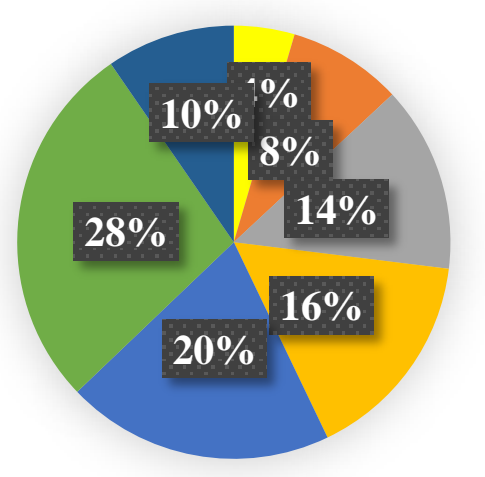

Paragominas - PA

Castanhal - PA

Bragantina - PA

Cametá - PA

- Tomé-Açu - PA

Guamá - PA

Segundo Alves et al (2014), a taxa de crescimento da produção de 2000-2011 da microrregião do Guamá foi de 8, 48\% ao ano, devido ao efeito da expansão da área colhida já que esta obteve a taxa de crescimento de $8,89 \%$ ao ano, enquanto que a produtividade nesse período diminuiu, pois, a taxa de crescimento foi de $-0,38 \%$, possivelmente devido incidência de doenças e manejo inadequado. Portanto, o crescimento da produção foi influenciado pela expansão da área.

Dentre os municípios da microrregião do Guamá o que se destacou no ano de 2015 foi Capitão Poço, produzindo 1.950 ton. de pimenta-do-reino. Porém, o município do estado do Pará que obteve a maior produção no ano de 2015 foi Igarapé-Açu com 3.120 ton. seguido de Tome-Açu com 2.560 ton. conforme o quadro 1.

Quadro 1 - Municípios que obtiveram as maiores produções de pimenta-do-reino no Estado do Pará, em 2015.

(Fonte: IBGE 2015).

\begin{tabular}{|c|c|}
\hline Município & QT produzida (ton.) \\
\hline Nova & 1.035 \\
\hline Esperança do Piriá - PA & 1.050 \\
\hline Paragominas - PA & 1.265 \\
\hline Garrafão do Norte - PA & 1.288 \\
\hline Castanhal - PA & 1.425 \\
\hline Cametá - PA & 1.440 \\
\hline Aurora do Pará - PA & 1.700 \\
\hline Acará - PA & 1.940 \\
\hline Concórdia do Pará - PA & 1.950 \\
\hline Capitão Poço - PA & 2.080 \\
\hline Baião - PA & 2.560 \\
\hline Tomé-Açu - PA & 3.120 \\
\hline Igarapé-Açu - PA & \\
\hline
\end{tabular}


Delimitação, caracterização e análise da cadeia produtiva

No Brasil, a pimenta-do-reino está entre as culturas mais importantes usada no processo de captação de renda por parte dos agricultores, principalmente os familiares, nas Regiões Norte e Nordeste do país. Entretanto, a estrutura de seu mercado, bem como as formas de relacionamento entre os agricultores familiares e as empresas processadoras, ainda são desconhecidas por grande parte dos agricultores (DESER, 2008).

O Brasil produz três tipos de pimenta para serem comercializadas no mercado internacional: a pimenta-preta, pimenta branca e em pequena escala a pimenta verde. Todas essas pimentas são a Piper nigrum, a diferença está no estádio de maturação em que são colhidas, e o beneficiamento dado a cada uma delas (DESER, 2008).

O custo de implantação de um novo pimental é considerado um dos maiores entraves dessa cadeia produtiva, pois, como as plantas necessitam de tutores (de aproximadamente 2 a 3 m de comprimento), a aquisição dos mesmos onera muito o custo inicial. Além da aquisição dos insumos agrícolas.

No entanto, no Estado do Pará o uso de tutor vivo tem despertado interesse de produtores e se torna uma alternativa viável para a substituição de estações de madeira, contribuindo assim para a redução dos impactos ambientais (MENEZES, 2016).

A cadeia produtiva começa com a etapa de aquisição dos insumos agrícolas, a qual está inserida "dentro da porteira", onde inicia-se pelo preparo da área que é feito com roçagem e distribuição do calcário em toda a área e, em seguida, é feita a gradagem. Após o preparo do solo, inicia-se a abertura das covas (MENEZES, 2016). Na fase de plantio, geralmente a pimenta-do-reino é plantada em sistema de monocultivo, por se tratar de uma espécie trepadeira são usados tutores de madeira para conduzir a planta. Neste caso, a pimenteira inicia a produção a partir de 2 anos de idade (DESER, 2008). Durante esse período são feitas adubações químicas e/ou orgânicas, os tratos culturais como controle das ervas daninhas por meio do uso do herbicida, capina, roçagem, coroamento e amarrio (MENEZES, 2016).

Para a produção de pimenta-do-reino é feita a colheita dos frutos, de coloração verde-claro, amarelada ou vermelha. Em seguida é feito o debulhamento manual ou mecânicos. O debulhamento consiste na separação das espigas de pimenta do pedúnculo a que estão aderidas, depois de separados os frutos são levados ao sol para secarem. Após a secagem os frutos são acondicionados em sacos e comercializados (DESER, 2008). Ao passar pelos intermediários, o destino da pimenta-do-reino acaba sendo as empresas exportadoras 
que são responsáveis pelo beneficiamento final da pimenta que passa por algumas etapas: ventilação, lavagem, secagem, classificação e acondicionamento do produto. Os exportadores para comercializarem a pimenta contam com os serviços de agentes de comercialização que intermedeiam a venda do produto no exterior (DESER, 2008).

\section{Conclusões}

Verificou-se por meio deste estudo que a conjuntura do mercado da pimenta-doreino está em expansão e é de suma importância conhecer a mesma para que os agentes econômicos envolvidos nessa atividade possam orientar-se e realizar um planejamento com base no mercado internacional.

Em relação ao panorama internacional, o Brasil encontra-se entre os primeiros colocados quando comparado às médias de produtividade em relação aos países concorrentes. Constatou-se também que a pimenta-do-reino, em muitos casos, está sendo cultivada em monocultivos sem a diversificação e os agricultores têm adotado práticas agrícolas que eleva os custos da implantação e manutenção da cultura, causando uma variabilidade nos preços.

Diante disso, os produtores tornam-se cada vez mais dependentes das variações de preços dos insumos agrícolas, o que impacta diretamente na renda deste agricultor. No entanto por se uma cultura exigente de nutrientes e susceptível a fusariose é imprescindível à busca por alternativas a fim de baratear o custo.

Em relação ao panorama regional, o estado do Pará ainda continua como maior produtor de pimenta-do-reino, no entanto, vem diminuindo a sua participação e o estado de Espírito Santo vem aumentando a sua participação durante os últimos anos. Quando se compara as microrregiões, percebe-se que a Bragantina tem maior destaque na produção do Estado. Em relação aos municípios do Estado, Igarapé-Açu possui maior quantidade produzida de pimenta-do-reino.

A cadeia produtiva da pimenta- do- reino é bem consolidada, pois há fornecimento de insumos até a chegada do produto ao consumidor final, passando por processos de comercialização e beneficiamento.

\section{Referências}

FILGUEIRAS, G. C et al. Fontes de crescimento da pimenta-do-reino no Estado do Pará no período de 19979 e 2001.In: Congresso da sociedade Brasileira de economia e sociologia rural, 42. Cuiabá, 2004. 
ALVES, J.D.N et al. Crescimento da produção de mandioca e pimenta-do-reino na microrregião do Guamá, Estado do Pará, no período de 2000-2011. Enciclopédia Biosfera, Centro Científico Conhecer - Goiânia, v.10, n.18; p.1792, 2014.

IBGE. Instituto Brasileiro de Geografia e Estatística-IBGE. Produção Agrícola nacional e regional. Disponível em: 〈http://www2.sidra.ibge.gov.br/>. Acessado em:03/04/2017.

FILGUEIRAS, G. C et al. Conjuntura do mercado da pimenta-do-reino no Brasil e no mundo. In: Workshop da Pimenta do Reino do Estado do Pará, Belém, PA. Situação atual e alternativa para a produção sustentável. Belém, PA: Embrapa Amazônia Oriental, 2009.

CÂMARA, J. J. R. Análise da competitividade das exportações de pimenta -do- do Pará e do Brasil no período de 1997 a 2007 e perspectivas de comércio. Universidade Federal do Ceará, Fortaleza, 2010. (Dissertação)

DESER. Departamento de estudos socioeconômicos. Secretaria de Agricultura Familiar. Curitiba, novembro, 2008.

FAO. Food and Agriculture of the United Nations. Statistical Databases. Disponível em: http://faostat.fao.org/faostat Acesso em: 20 de abril de 2017.

HOMMA, A. K. O. Extrativismo, Biodiversidade e Biopirataria na Amazônia. BrasíliaDF, Embrapa Informação Tecnológica, 2008.

LOURINHO et al. Conjuntura da pimenta-do-reino no mercado nacional e na região norte do Brasil. Enciclopédia Biosfera, Centro Científico Conhecer - Belém, PA, 2014. MENEZES, A. J. A et al. Cultivo da pimenta do reino (Piper nigrum L.) com tutor vivo de gliricidia (Gliricidia sepium L.) para produão no Estado do Pará. Revista de Agropecuaria da Embrapa Amazônia Oriental, 2016. 